\title{
Glycoprotein Ilb/Illa inhibitors for cardiogenic shock complicating acute myocardial infarction: a systematic review, meta-analysis, and meta-regression
}

Carolina Saleiro $^{1 *} \mathbb{D}$, Rogério Teixeira ${ }^{1,2,3}$, Diana De Campos ${ }^{1}$, João Lopes ${ }^{1}$, Bárbara Oliveiros ${ }^{2,3}$, Marco Costa ${ }^{1}$ and Lino Gonçalves ${ }^{1,2,3}$

\begin{abstract}
Background: Cardiogenic shock complicates 5-10\% of myocardial infarction (MI) cases. Data about the benefit of glycoprotein Ilb/llla inhibitors (GPI) in these patients is sparse and conflicting.

Methods: We performed a systematic review, meta-analysis, and meta-regression of studies assessing the impact of GPI use in the setting of Ml complicated cardiogenic shock on mortality, angiographic success, and bleeding events. We systematically searched for studies comparing GPI use as adjunctive treatment versus standard care in this setting. Random-effects meta-analysis and meta-regression were performed.

Results: Seven studies with a total of 1216 patients (GPI group, 720 patients; standard care group, 496 patients) were included. GPI were associated with a $45 \%$ relative reduction in the odds of death at 30 days (pooled OR $0.55 ; 95 \% \mathrm{Cl}$ $0.35-0.85 ; P^{2}=57 \% ; P=0.007$ ) and a $49 \%$ reduction in the odds of death at 1 year (pooled OR $0.51 ; 95 \% \mathrm{Cl} 0.32-0.82 ; P^{2}$ $=58 \% ; P=0.005$ ). Reduction in short-term mortality seemed to be more important before 2000 , as this benefit disappears if only the more recent studies are analyzed. GPI were associated with a 2-fold increase in the probability of achieving TIMI 3 flow (pooled OR, 2.05; 95\% Cl 1.37-3.05; $P^{2}=37 \%, P=0.0004$ ). Major bleeding events were not increased with GPI therapy (pooled OR, 1.0; $95 \% \mathrm{Cl} 0.55-1.83 ; P^{2}=1 \%, P=0.99$ ). Meta-regression identified that patients not receiving an intra-aortic balloon pump seemed to benefit the most from GPI use ( $Z=-1.57, P=0.005)$.
\end{abstract}

Conclusion: GPI therapy as an adjunct to standard treatment in cardiogenic shock was associated with better outcomes, including both short- and long-term survival, without increasing the risk of bleeding.

Keywords: Glycoprotein Ilb/llla inhibitors, Abciximab, Eptifibatid, Cardiogenic shock

\section{Background}

Cardiogenic shock complicates 5 to $10 \%$ of myocardial infarction (MI) cases $[1,2]$. Apart from immediate revascularization, no other treatment has been shown to improve outcomes, and reported intra-hospital mortality

\footnotetext{
*Correspondence: saleiro.cs@gmail.com

'Serviço de Cardiologia, Centro Hospitalar e Universitário de Coimbra, Quinta dos Vales, 3041-801 Coimbra, Portugal

Full list of author information is available at the end of the article
}

ranges from 23 to $44 \%$ [3, 4]. Further, optimal treatment options are still debated. These features underscore the difficulty in conducting trials in this setting.

Activation of the platelet glycoprotein IIb/IIIa receptor is the final common pathway in the process leading to platelet aggregation, making glycoprotein IIb/IIIa inhibitors (GPI) the most powerful antiplatelet drugs [5]. Their valuable effects in patients with acute coronary syndrome (ACS) have been shown in several trials. A 
recent meta-analysis of 21 randomized controlled trials by Karathanos et al. found that routine GPI use in STelevation myocardial infarction (STEMI) significantly reduced not only the risk for mortality at 30 days and 6 months but also for recurrent ischemic events [6]. However, this was at the cost of an increased risk for all bleeding outcomes, except for intracranial hemorrhage [6]. Most of the studies included a low percentage of patients with shock and were conducted in the era before routine use of novel oral P2Y12 receptor antagonists [7, 8].

Currently, the 2017 European Society Guidelines for the management of acute STEMI recommend considering GPI as a bailout therapy in the event of angiographic evidence of a large thrombus, slow or no reflow, and other thrombotic complications (recommendation class IIa; level C) [9]. In the setting of MI complicated by cardiogenic shock or after cardiopulmonary resuscitation, the best antiplatelet treatment is not currently known. Acetylsalicylic acid may be given intravenously (IV), but most P2Y12 inhibitors must be given orally and most patients in this setting do not have a patent oral route. Although there is the possibility of crushing or dissolving tablets and administering them via a nasogastric tube, many unstable patients may not be intubated by the time they reach the cath lab. Also, gastroparesis and delayed gut absorption may be expected in such patients [10]. This leads to the theory that adjunctive use of GPI is a good choice in cardiogenic shock patients, mainly because of the IV use, high potency, and rapid onset of action. Currently, data about the benefit of GPI in these patients is sparse and conflicting.

We conducted a review aiming to collect available evidence regarding the use of GPI in the context of acute MI complicated by cardiogenic shock. Also, we conducted a meta-analysis and meta-regression to evaluate the impact of GPI use in these patients on short- and long-term mortality, successful revascularization on angiography, and major bleeding.

\section{Methods}

\section{Study identification and selection}

We searched MEDLINE, Embase, and the Cochrane Library databases using the key terms "glycoprotein IIb/ IIIa inhibitors" or "abciximab" or "tirofiban" or "eptifibatide" and "cardiogenic shock" without language or date restriction in April 2020. We also manually searched the references from the articles of interest to identify other potentially relevant studies. This data meta-analysis was conducted in accordance with the PRISMA statement. The papers to be included were selected according to a 3 -step methodology: (1) reading the title and evaluating its relevance, (2) reading the abstract, and (3) reading the full text.
Articles were considered for inclusion in the analysis if (1) they included a population of patients with cardiogenic shock complicating acute MI and (2) had available data regarding comparisons between groups treated with standard care with adjunctive GPI use and standard care without GPI and (3) data of at least 30-day or 1-year mortality. No strict definition for cardiogenic shock was considered as an inclusion criteria; rather, it was accepted as defined by each research group of the included studies (see Table 1). Standard care was also accepted as the treatment offered to each individual patient, considering that it was the best treatment option for each unique clinical situation. Major bleeding events were included as defined by each study group and are summarized in Table 1. Observational studies were accepted for inclusion. Exclusion criteria included duplicate publication and studies published only in the form of an abstract or as oral conference presentations. Two authors systematically screened the titles and abstracts of publications retrieved using the search strategy in order to select studies which met the inclusion criteria. Any disagreement between them over the eligibility of studies was resolved through discussion and involvement of a third author.

A total of 248 studies were identified. Of these, 234 were excluded after title/abstract analysis, as it was evident that they did not fulfill the inclusion criteria or contained duplicate findings. Four studies were excluded after complete analysis because there was not enough data to conduct our analysis or there was no direct comparison between groups of interest. One study was excluded because it was a sub-analysis of another included trial, and another was excluded because it showed only intra-hospital mortality. Another was excluded because the full text was available only in Russian. The selection diagram is shown in Fig. 1. Study design and characteristics were collected from all studies included in the analysis. Data regarding age, gender, hypertension, diabetes mellitus, tobacco use, previous MI, 3-vessel disease, left main disease, left ventricular ejection fraction (LVEF), invasive mechanical ventilation, intra-aortic balloon pump (IABP), and thrombolysis in myocardial infarction (TIMI) flow pre- and post-procedure were considered relevant for cohort characterization and were also collected, when available.

The primary endpoint was 30-day mortality. Secondary endpoints were 1-year mortality, successful revascularization on angiography, and major bleeding. The impact of age, gender, hypertension, diabetes mellitus, tobacco use, mechanical ventilation, LVEF, TIMI flow 0/1 preprocedure, IABP pump use, or left main lesion on 30day mortality between groups was analyzed by a metaregression. 


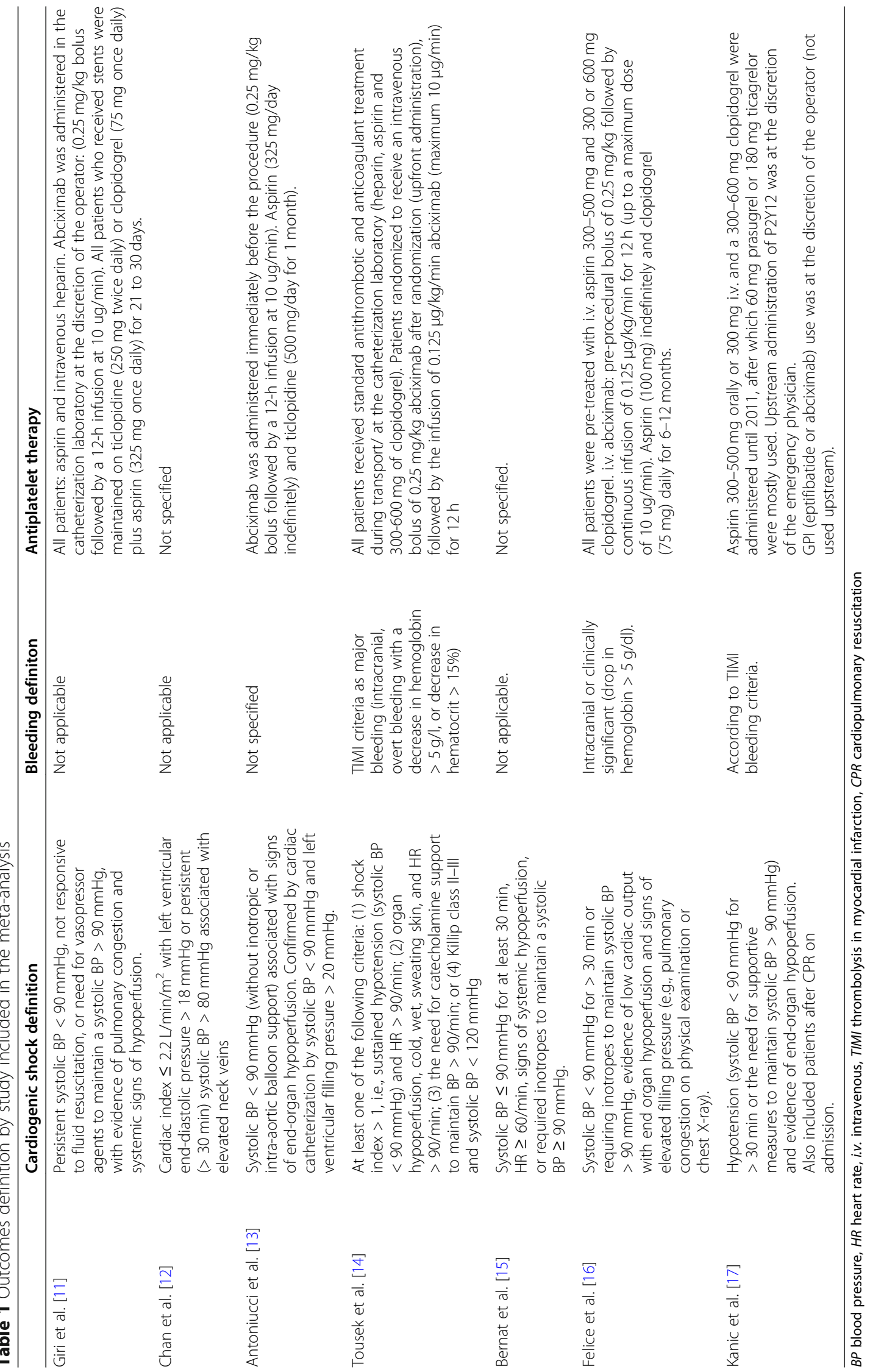




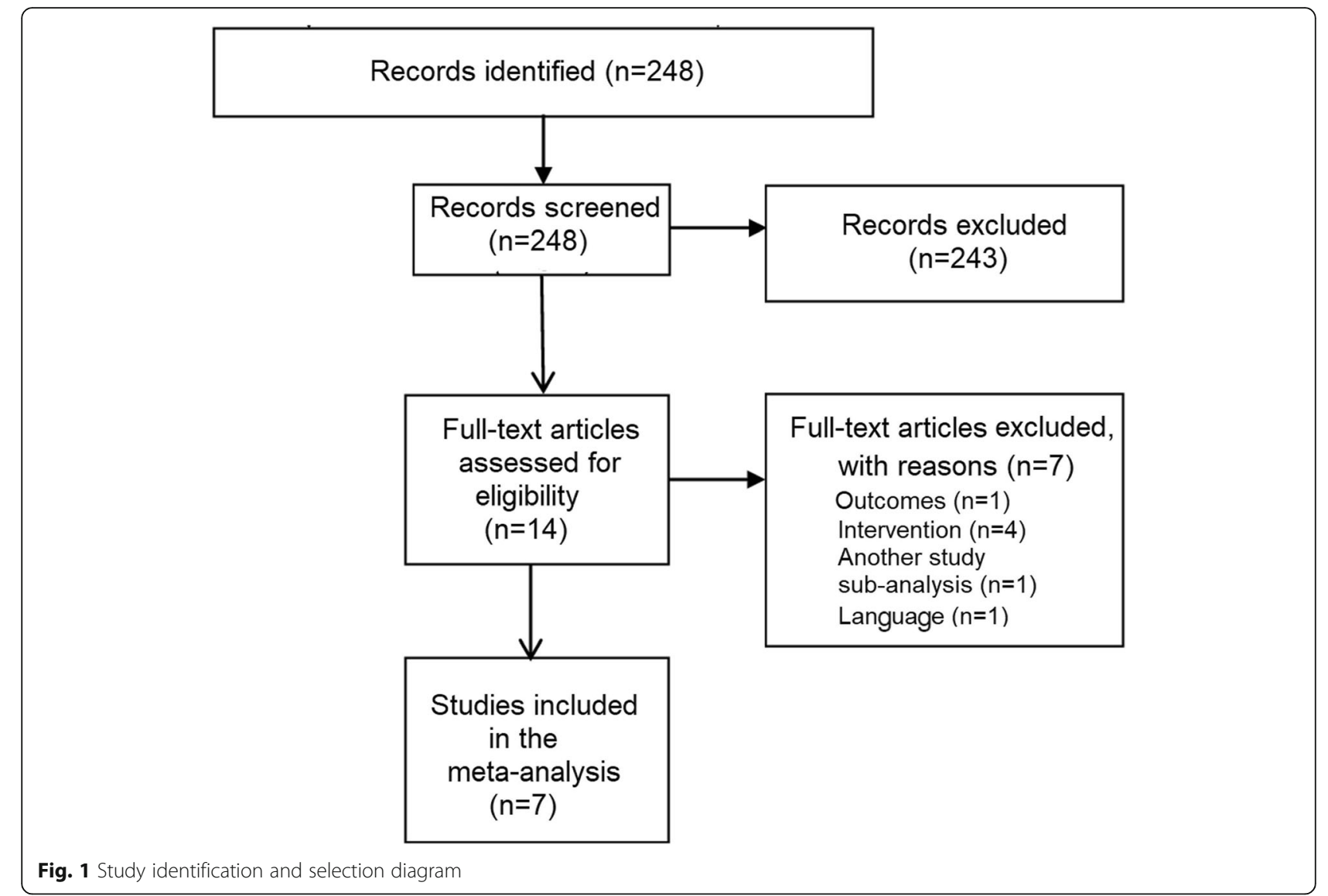

Cardiogenic shock and major bleeding definition, as well as antiplatelet therapy by study included, is shown in Table 1.

\section{Risk of bias assessment}

Two authors independently assessed the risk of bias of the included articles, following the Cochrane Collaboration's "Risk of bias" tool. Studies were assessed as "low," "high," or "unclear" risk for the following biases: random sequence generation, allocation concealment, blinding of participants and personnel, blinding of outcome assessment, incomplete outcome data, and selective reporting. The quality assessment for each study is presented in the "risk of bias summary" (Fig. 2).

\section{Statistical analysis}

Continuous variables are expressed as mean \pm standard deviation for normally distributed data or median and interquartile range for non-normally distributed data, and categorical variables are expressed as frequencies or percentages. Pooled odds ratios (OR) and 95\% confidence intervals $(\mathrm{CI})$ were estimated based on a random effects meta-analysis and were obtained from the pooled adjusted OR of primary studies. Statistical significance was accepted for $P$ values $<0.05$. The $I^{2}$ statistic was used to assess statistical heterogeneity across studies (moderate heterogeneity was considered present for values between 30 and 60\%). Meta-regression was conducted according to the mixed-effects model. We used Review Manager 5.2 (Nordic Cochrane Centre, London, UK) software to perform statistical analyses. The metaregression was performed using $\mathrm{R}$ software through $\mathrm{R}$ Studio, version 1.1.463 ( $\mathrm{R}$ Foundation for Statistical Computing, Vienna, Austria).

\section{Results}

\section{Studies for the analysis}

Seven studies that comprised a total of 1216 patients were included in the analysis (720 patients in the GPI group and 496 patients in the standard treatment group). In the GPI group, $66 \%$ of the patients received abciximab and $22 \%$ received eptifibatide; for $12 \%$ of the patients, the GPI received was not reported. Only 1 study was a randomized trial [14]; all the others had an observational design [11-13, 15-17]. The details of the studies included in the analysis are displayed in Table 2.

\section{Baseline characteristics}

The mean age of the study population was similar between groups $(66.6 \pm 12.6$ years in the GPI group vs. 


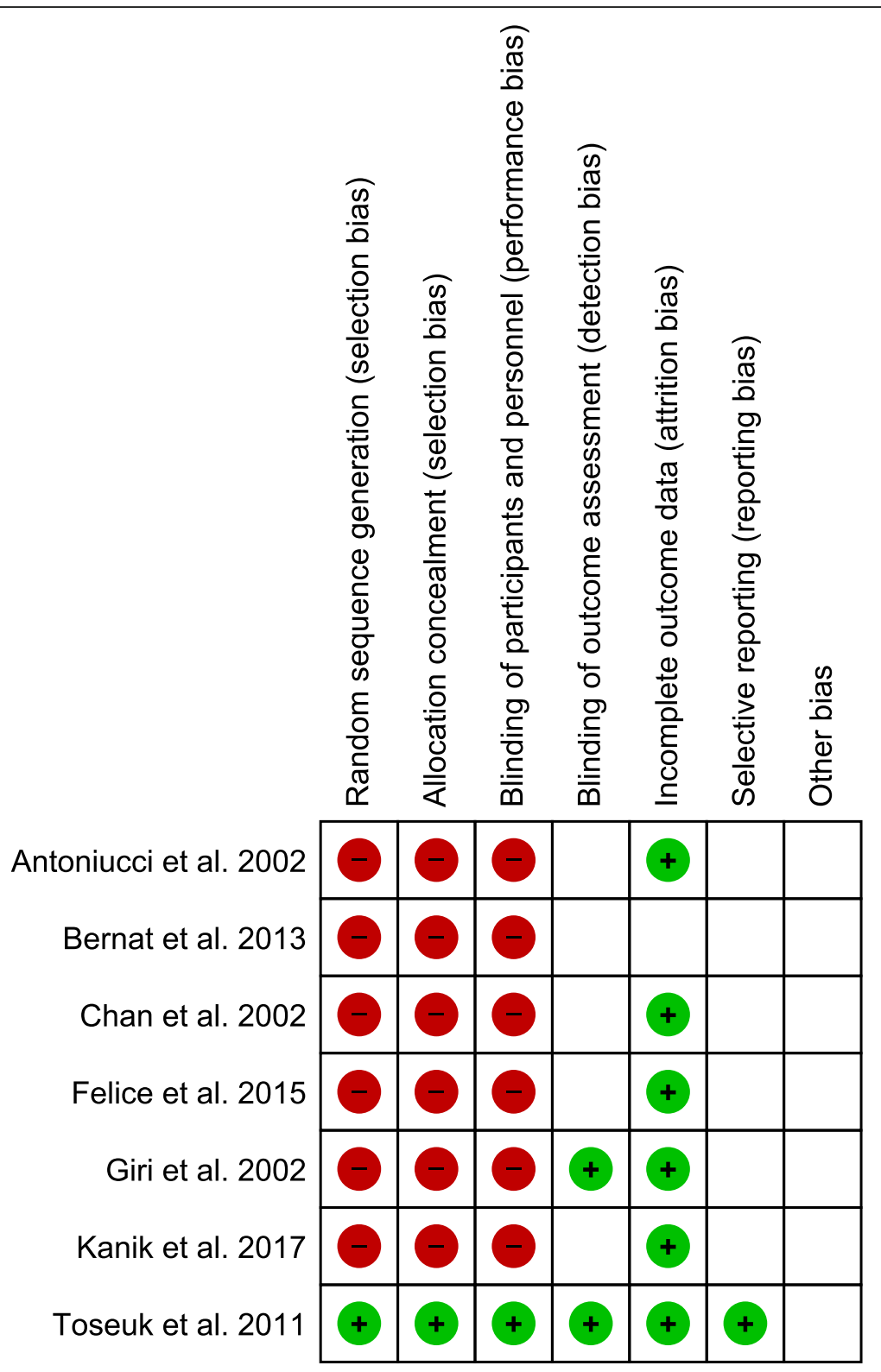

Fig. 2 Risk of bias summary. Red, high risk of bias; blank space unclear risk of bias; green, low risk of bias

$69.1 \pm 12.3$ years in the standard treatment group). There were more males and tobacco users in the standard treatment group, and there were more hypertensive patients in the GPI group. No other important differences between groups were noted. The baseline characteristics are listed in Table 3.

\section{Short-term (30-day) mortality}

All studies were primarily designed to evaluate the use of GPI on 30-day mortality: a total of 1037 patients were evaluated for this endpoint. In all, $37 \%$ of patients were dead at 30 days in the GPI group compared to $50 \%$ in the standard care group. GPI use was associated with a significant $45 \%$ relative reduction in the odds of death (Fig. 3) (OR 0.55; 95\% CI 0.35-0.85; $I^{2}=57 \% ; P=$ $0.007)$. However, there was moderate heterogeneity between studies with respect to outcomes $\left(I^{2}=57 \%\right.$; $P=$ 0.04). In a sensitivity analysis, after excluding studies that included patients until 2000 [11-13], resulting in a total of 751 patients and 340 pooled events, GPI use was no longer associated with 30-days mortality (Fig. 4) (OR $0.78 ; 95 \%$ CI $0.40-1.52 ; I^{2}=74 \% ; P=0.46$ ). There was still substantial heterogeneity between studies with respect to the outcome $\left(I^{2}=74 \% ; P=0.02\right)$.

Meta-regression for age, gender, hypertension, diabetes mellitus, tobacco use, mechanical ventilation, LVEF, 
Saleiro et al. Journal of Intensive Care

(2020) 8:85

Page 6 of 12

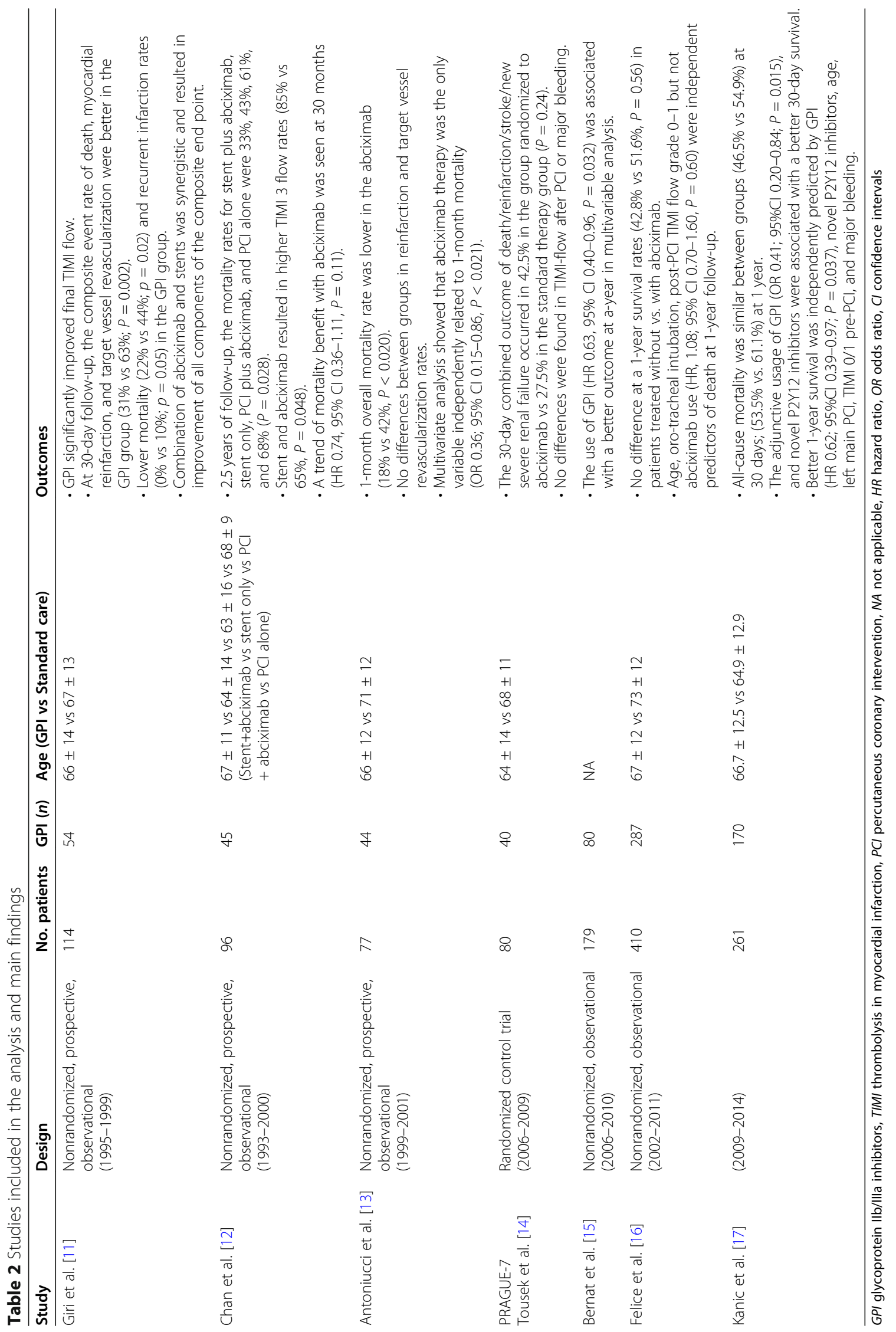


Table 3 Baseline characteristics

\begin{tabular}{|c|c|c|c|c|c|c|}
\hline Analysis & GPI & Standard treatment & MD & $95 \% \mathrm{Cl}$ & $P$ value & $I^{2}(\%)$ \\
\hline Age & $66.6 \pm 12.6$ & $69.1 \pm 12.3$ & -2.75 & -0.64 to 0.83 & 0.13 & 74 \\
\hline LVEF & $35 \pm 9$ & $32 \pm 10$ & 0.33 & -1.83 to 2.49 & 0.63 & 27 \\
\hline Analysis & GPI & Standard treatment & OR & $95 \% \mathrm{Cl}$ & $P$ value & $I^{2}(\%)$ \\
\hline Gender (male)* & $470 / 640$ & $258 / 397$ & 1.43 & $1.09-1.89$ & 0.01 & 8 \\
\hline Diabetes mellitus & $112 / 470$ & $90 / 306$ & 0.77 & $0.55-1.08$ & 0.13 & 0 \\
\hline Hypertension* & $247 / 425$ & $168 / 225$ & 0.68 & $0.49-0.94$ & 0.02 & 74 \\
\hline Tobacco use* & $197 / 470$ & $87 / 306$ & 1.87 & $1.20-2.91$ & 0.006 & 36 \\
\hline Previous MI & $82 / 470$ & 77/306 & 0.75 & $0.48-1.18$ & 0.21 & 25 \\
\hline 3 vessel disease & $181 / 425$ & $124 / 225$ & 0.64 & $0.29-1.45$ & 0.29 & 79 \\
\hline Left main lesion & $74 / 446$ & $31 / 298$ & 1.54 & $0.52-4.57$ & 0.44 & 76 \\
\hline Invasive ventilation & $312 / 586$ & $198 / 338$ & 1.20 & $0.62-2.23$ & 0.57 & 65 \\
\hline IABP & $363 / 640$ & 149/397 & 2.13 & $0.96-4.72$ & 0.06 & 82 \\
\hline TIMI 0/1 pre-procedure & $167 / 595$ & $185 / 346$ & 0.60 & $0.19-1.88$ & 0.38 & 90 \\
\hline
\end{tabular}

Bernat et al.'s study did not provide information regarding baseline data and was therefore not included in the baseline characteristics analysis GPI glicoprotein Ilb/IIla inhibitors, MD mean difference, $C I$ confidence intervals, OR odds ratio, $L V E F$ left ventricular ejection fraction, $M I$ myocardial infarction, IABP intraortic balloon pump, TIMI thrombolysis in myocardial infarction

TIMI flow 0/1 pre-procedure, or left main culprit lesion revealed no statistically significant differences (Table 4). Only the inclusion of the IABP variable in the metaregression influenced the outcome $(Z=-1.57, P=$ 0.005) (Table 4), and GPI use was associated with a higher OR when patients did not receive an IABP.

\section{Long-term mortality}

Three observational studies including 850 patients reported 1-year mortality. Mortality was $47 \%$ in the GPI group and $60 \%$ in the standard care group. The pooled analysis (Fig. 5) showed a $49 \%$ reduction in the odds of 1 -year mortality in favor of the GPI group (OR 0.51; 95\% CI 0.32-0.82; $I^{2}=58 \% ; P=0.005$ ).

\section{Successful revascularization: TIMI 3 flow after PCI}

TIMI 3 flow after PCI was achieved in $84 \%$ of the patients in the GPI group and 70\% in the standard care group. The pooled data showed that adjunctive use of GPI was associated with a 2 -fold increase in the probability of achieving TIMI 3 flow after PCI (Fig. 6) (OR 2.05; 95\% CI $\left.1.37-3.05 ; I^{2}=37 \%, P=0.0004\right)$. Antoniucci et al. reported only data regarding successful angioplasty (not specific for TIMI 3 flow). When this study was included in the analysis, the results were similar to those presented for TIMI 3 flow (data not shown). In a sensitivity analysis, after excluding studies that included patients until 2000 $[11,12]$, GPI use is still associated with a higher odds of achieving TIMI 3 flow (Fig. 7) (OR 1.81; 95\% CI 1.21$\left.2.69 ; I^{2}=25 \%, P=0.004\right)$. This sensitivity analysis reduced heterogeneity between studies with respect to outcomes $\left(I^{2}=0.25, P=0.26\right)$.

\section{Safety endpoints: major bleeding events}

Bleeding events were reported in 4 studies involving a total of 829 patients (541 treated with GPI). The risk of major bleeding was not significantly increased with GPI therapy compared with standard treatment (Fig. 8) (OR,

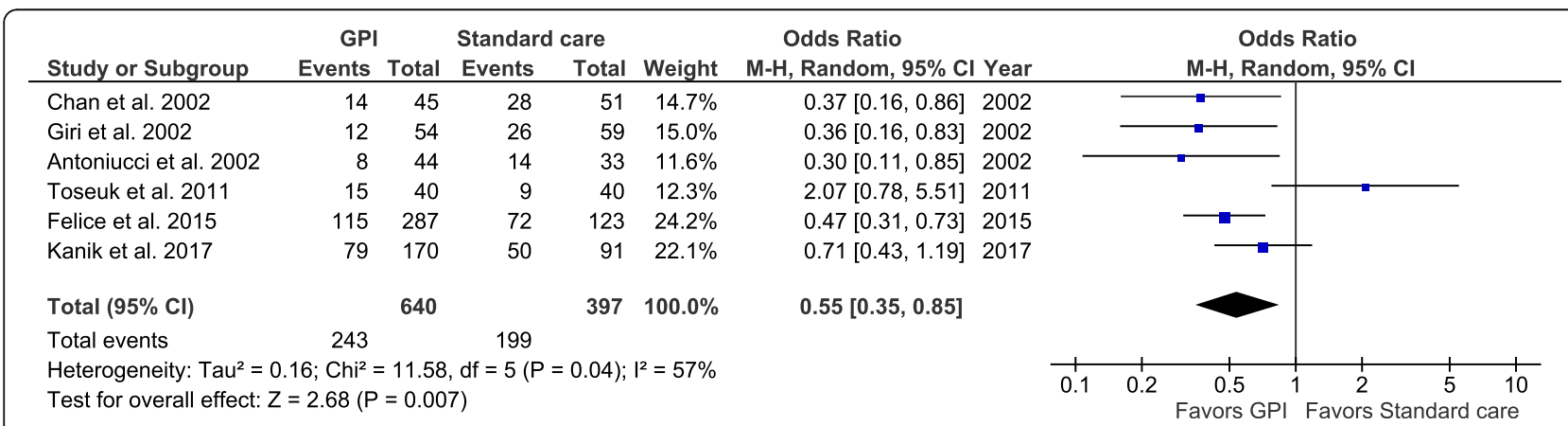

Fig. 3 Pooled analysis for 30-day mortality comparing GPI and standard care. Numbers displayed represent ORs with $95 \% \mathrm{Cls}$. Cl, confidence interval; GPI, glycoprotein IIb/IIla inhibitors; OR, odds ratio 


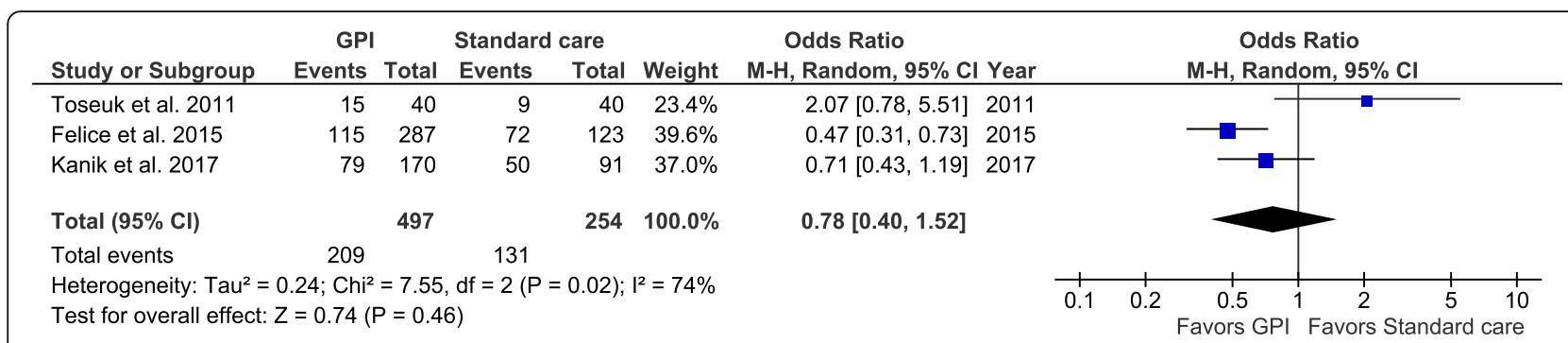

Fig. 4 Sensitivity analysis for 30-day mortality comparing GPI and standard care. Numbers displayed represent ORs with 95\% Cls. Cl, confidence interval; GPI, glycoprotein Ilb/llla inhibitors; OR, odds ratio

1.0; $95 \%$ CI $\left.0.55-1.83 ; I^{2}=1 \%, P=0.99\right)$. In a sensitivity analysis, after excluding studies that included patients until 2000, GPI use did not increase the risk of bleeding (Fig. 9) (OR 0.97; 95\% CI 0.44-2.13; $I^{2}=28 \%, P=0.94$ ).

\section{Discussion}

Our meta-analysis showed that among patients with cardiogenic shock complicating MI, GPI adjunctive use may be both effective and safe. Overall, 30-day and 1-year mortality were both almost halved with the use of GPI compared to standard treatment only. The cohort of patients not receiving an IABP benefited the most from GPI use. However, this reduction in short-term mortality seemed to be more important before 2000, as this benefit disappeared if only the more recent studies are analyzed. GPI adjunctive treatment was similarly associated with angiographic success: there was a 2-fold increase in the odds of achieving a TIMI 3 flow after PCI in this group. Also, GPI use adjunctive to standard care showed a good safety profile as it did not increase the risk for major bleeding events.

All studies except one (Prague-7) were observational in nature. In these studies, GPI use and revascularization strategy were at the discretion of the operator and varied depending on time and setting. Older studies included a low number of patients with PCI with stent implantation [11-13]; as in one study, balloon only angioplasty accounted for $57 \%$ of all PCIs [11]. Most of the dual antiplatelet therapy consisted of ticlopidine or clopidogrel plus aspirin [11-13]. Until 2011, anti-platelet loading doses consisted of aspirin and/or clopidogrel [16, 17]. More recently, prasugrel or a loading dose of ticagrelor was mostly used concomitantly with aspirin. Abciximab was administered as a bolus followed by continuous infusion. Only a small proportion of patients were treated with a GPI other than abciximab $[15,17]$. The Prague- 7 trial differed from these observational studies in the fact that a group was randomized to receive upfront administration of abciximab adjunctive to standard therapy, while in the control group, abciximab was administered if deemed necessary by the operator [14]. This study included not only patients in cardiogenic shock but also patients at risk for evolving to cardiogenic shock; in fact, only 47 of the 80 patients included were considered class Killip-Kimbal IV [14]. Kanic et al. also included patients resuscitated from sudden death (161 out of 261 patients), not only patients in cardiogenic shock [17]. See Table 1 for further details. Despite varying cardiogenic shock definitions, all patients included were considered critically ill.

Table 4 Meta-regression for 30-day mortality

\begin{tabular}{lllll}
\hline & $\boldsymbol{n}$ & $\boldsymbol{I}^{\mathbf{2}}$ & $\mathbf{Q}_{\mathbf{d f}}(\boldsymbol{p})$ & \multicolumn{1}{c}{ Coef $(\boldsymbol{p})$} \\
\hline Age & 5 & $61.32 \%$ & $7.32_{3}(0.062)$ & $-0.307(0.210)$ \\
Gender & 6 & $51.72 \%$ & $8.72_{4}(0.068)$ & $4.475(0.169)$ \\
Diabetes mellitus & 6 & $68.09 \%$ & $10.42_{4}(0.034)$ & $-0.849(0.708)$ \\
Hypertension & 3 & $85.10 \%$ & $6.71_{1}(0.010)$ & $6.832(0.387)$ \\
Tobacco use & 4 & $81.47 \%$ & $8.111_{2}(0.017)$ & $6.774(0.456)$ \\
Invasive ventilation & 5 & $77.08 \%$ & $10.614_{3}(0.014)$ & $-0.165(0.893)$ \\
TIMI flow 0/1 pre procedure & 5 & $77.28 \%$ & $10.681_{3}(0.014)$ & $-0.288(0.807)$ \\
IABP use* & 6 & $0.00 \%$ & $3.762_{4}(0.439)$ & $-1.565(0.005)$ \\
LVEF & 3 & $0.00 \%$ & $0.002_{1}(0.989)$ & $-0.665(0.368)$ \\
Left main stenosis & 4 & $41.01 \%$ & $3.279_{2}(0.194)$ & $-15.572(0.851)$ \\
\hline
\end{tabular}

$n$ number of studies included in the analysis, TIMI thrombolysis in myocardial infarction, IABP intraortic balloon pump, LVEF left ventricular ejection fraction 


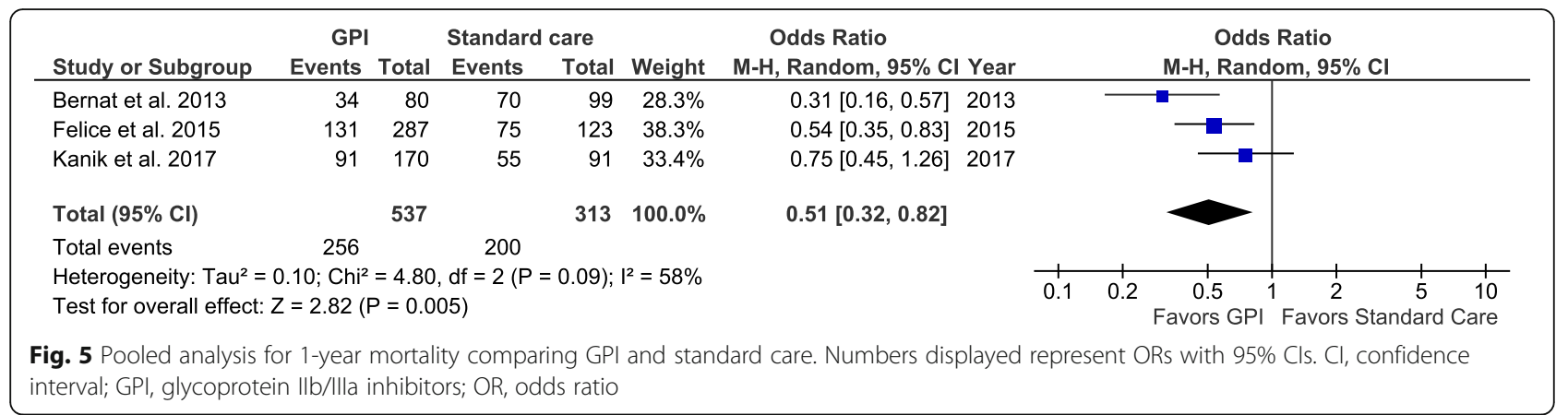

An analysis from 2005 to 2013 showed a reduction in the use of GPI from 76 to 53\% [3], and another study showed a similar decrease from $93 \%$ in 2010 to $44 \%$ in 2014 [17]. Bivalirudin and novel P2Y12 inhibitors (prasugrel/ticagrelor) were used less often in the GPI group. However, in a multivariable analysis, the year of admission was not a predictor of worse outcome [17]. Younger patients without the need for IABP support or orotracheal intubation were more likely to receive abciximab treatment [16]. No differences between groups regarding invasive ventilation and IABP support were noted. Finally, we cannot make assumptions regarding the standard medical therapy as it was not detailed in any of the included studies.

Antoniucci et al. suggested that the clinical benefit of GPI was not related to the patency of the infarct-related artery, as there was no benefit in events related to vessel reocclusion such as reinfarction or need for repeat revascularization. Moreover, most deaths were due to refractory ventricular failure, regardless of a patent vessel [13]. It was hypothesized that abciximab prevents recurrent MI not only via its potent antiplatelet activity but also due to its possible anti-inflammatory effects [18], allowing rapid recovery of coronary vascular function in the microcirculation [19]. The positive effect on coronary microvasculature is mediated by the inhibition of direct interaction of platelets and leukocytes with reperfused endothelium, along with a diminished distal embolization of platelet aggregates [18] Abciximab also permits a more rapid recovery of regional wall motion and ventricular function [19]. This is critical in cardiogenic shock patients and may, in part, explain the better outcomes in mortality that we found.

Despite our results, it is difficult to unreservedly support the routine adjunctive use of GPI in cardiogenic shock patients in the era of novel P2Y12 inhibitors and new revascularization strategies, as they were underrepresented in this meta-analysis. We sought to overcome this handicap by performing a sensitivity analysis excluding studies that included patients before 2000. We chose this timeline because of the publication of the SHOCK trial in 1999 [20]. This trial was the first prospective randomized study in cardiogenic shock. Emergency early revascularization with coronary artery bypass graft or PCI was compared with a strategy of initial medical stabilization with drug therapy and IABP. Mortality rate at 6 months was significantly improved in the early revascularization group, although no difference was noted on 30-day mortality [20]. It had strong impact on clinical care in MI complicated by cardiogenic shock as early revascularization was not clinical standard care before that [20]. In fact, the advantage conferred by GPI in shortterm mortality disappeared after exclusion of older studies, while maintaining long-term survival benefit. Still, the IV use of GPI and their rapid onset of action may denote an important advantage for their use in this

\begin{tabular}{|c|c|c|c|c|c|c|c|c|c|c|}
\hline \multirow[b]{2}{*}{ Study or Subgroup } & \multicolumn{2}{|c|}{ GPI } & \multicolumn{2}{|c|}{ Standard care } & \multirow[b]{2}{*}{ Weight } & \multirow{2}{*}{$\begin{array}{l}\text { Odds Ratio } \\
\text { M-H, Random, } 95 \% \text { Cl Year }\end{array}$} & \multirow{2}{*}{\multicolumn{3}{|c|}{$\begin{array}{l}\text { Odds Ratio } \\
\text { M-H, Random, } 95 \% \mathrm{Cl} \\
\end{array}$}} & \\
\hline & Events & Total & Events & Total & & & & & & \\
\hline Chan et al. 2002 & 35 & 45 & 33 & 51 & $14.3 \%$ & $1.91[0.77,4.73] 2002$ & \multirow{2}{*}{\multicolumn{2}{|c|}{7}} & \multicolumn{2}{|l|}{$\square$} \\
\hline Giri et al. 2002 & 47 & 54 & 34 & 59 & $13.4 \%$ & $4.94[1.91,12.73] 2002$ & & & & \\
\hline Toseuk et al. 2011 & 28 & 40 & 29 & 40 & $13.0 \%$ & $0.89[0.34,2.33] 2011$ & & & & \\
\hline Felice et al. 2015 & 226 & 287 & 81 & 123 & $31.4 \%$ & $1.92[1.20,3.07] 2015$ & & & & \\
\hline Kanik et al. 2017 & 124 & 170 & 50 & 91 & $27.8 \%$ & $2.21[1.30,3.77] 2017$ & & & & \\
\hline Total $(95 \% \mathrm{Cl})$ & \multirow{2}{*}{\multicolumn{2}{|c|}{460}} & & 364 & $100.0 \%$ & \multirow[t]{2}{*}{$2.05[1.37,3.05]$} & & & & \\
\hline Total events & & & 227 & & & & & & & \\
\hline \multicolumn{7}{|c|}{$\begin{array}{l}\text { Heterogeneity: } \mathrm{Tau}^{2}=0.07 ; \mathrm{Chi}^{2}=6.37, \mathrm{df}=4(P=0.17) ;\left.\right|^{2}=37 \% \\
\text { Test for overall effect: } Z=3.52(P=0.0004)\end{array}$} & $\begin{array}{ll}1 & 1 \\
0.1 & 0.2 \\
\text { Favors Sta }\end{array}$ & 0.5 & $\begin{array}{cc}2 & 4 \\
\text { Favors GPI } & \end{array}$ & 10 \\
\hline \multicolumn{11}{|c|}{$\begin{array}{l}\text { Fig. } 6 \text { Pooled analysis for TIMI } 3 \text { flow after PCI comparing GPI and standard care. Numbers displayed represent ORs with } 95 \% \text { Cls. Cl, confidence } \\
\text { interval; GPI, glycoprotein Ilb/IIla inhibitors; OR, odds ratio; TIMI, thrombolysis in myocardial infarction. Please note that for easy understanding } \\
\text { "standard care" is represented "left" and "GPI" is presented "right" in the forest plot }\end{array}$} \\
\hline
\end{tabular}




\begin{tabular}{|c|c|c|c|c|c|c|c|c|c|c|}
\hline \multirow[b]{2}{*}{ Study or Subgroup } & \multicolumn{2}{|c|}{ Experimental } & \multicolumn{2}{|c|}{ Control } & \multicolumn{2}{|r|}{ Odds Ratio } & \multirow{2}{*}{\multicolumn{2}{|c|}{$\begin{array}{l}\text { Odds Ratio } \\
\text { M-H, Random, } 95 \% \mathrm{Cl}\end{array}$}} & & \\
\hline & Events & Total & Events & Total & Weight & M-H, Random, 95\% Cl Year & & & & \\
\hline Toseuk et al. 2011 & 28 & 40 & 29 & 40 & $15.0 \%$ & $0.89[0.34,2.33] 2011$ & $\longrightarrow$ & & & \\
\hline Felice et al. 2015 & 226 & 287 & 81 & 123 & $46.2 \%$ & $1.92[1.20,3.07] 2015$ & & $\longrightarrow$ & & \\
\hline Kanik et al. 2017 & 124 & 170 & 50 & 91 & $38.8 \%$ & $2.21[1.30,3.77] 2017$ & & & & \\
\hline Total $(95 \% \mathrm{Cl})$ & & 497 & & 254 & $100.0 \%$ & $1.81[1.21,2.69]$ & & & & \\
\hline Total events & 378 & & 160 & & & & & & & \\
\hline $\begin{array}{l}\text { Heterogeneity: } \mathrm{Tau}^{2}= \\
\text { Test for overall effect: }\end{array}$ & $\begin{array}{l}0.03 ; \mathrm{Chi}^{2} \\
\mathrm{Z}=2.90(\mathrm{P}\end{array}$ & $\begin{aligned} & 2.68, \mathrm{~d} \\
= & 0.004\end{aligned}$ & $f=2(P=$ & $0.26)$ & $I^{2}=25 \%$ & & $\begin{array}{ccc}0.1 & 0.2 & 0.5 \\
\text { Favors Standard care }\end{array}$ & $\begin{array}{c}2 \\
\text { Favors GPI }\end{array}$ & 5 & 10 \\
\hline $\begin{array}{l}\text { Fig. } 7 \text { Sensitivity analys } \\
\text { confidence interval; GP } \\
\text { understanding "standar }\end{array}$ & $\begin{array}{l}\text { s for TIMI } \\
\text { glycoprot } \\
\text { d care" is re }\end{array}$ & $\begin{array}{l}\text { flow a } \\
\text { in Ilb/II } \\
\text { present }\end{array}$ & $\begin{array}{l}\text { fter PCl c } \\
\text { la inhibit } \\
\text { ted "left" }\end{array}$ & and " $\mathrm{G}$ & $\begin{array}{l}\text { ring GPI ar } \\
\mathrm{R} \text {, odds rat } \\
\text { GPI" is pres }\end{array}$ & $\begin{array}{l}\text { nd standard care. Numbers dis } \\
\text {-io; TIMI, thrombolysis in myoc } \\
\text { sented "right" in the forest plo }\end{array}$ & $\begin{array}{l}\text { played represent ORs wi } \\
\text { ardial infarction. Please } n\end{array}$ & $\begin{array}{l}\text { ith } 95 \% \mathrm{Cls} \text {. } \\
\text { note that for }\end{array}$ & & \\
\hline
\end{tabular}

setting. The new IV P2Y12 inhibitor cangrelor is showing good results in patients with cardiogenic shock, but much still needs to be clarified about its use [21].

\section{Impact of GPI use on mortality}

Concordant with our results showing a positive impact on prognosis, four other studies found that abciximab therapy improves the 30-day outcome of primary PCI in cardiogenic shock [11-13, 17]. Other studies, which were not included in the analysis, also support the benefit of adjunctive use of GPI on in-hospital [22] and 30day mortality [23]. In a larger study, however, abciximab use was not a predictor of death after multivariable adjustment [16]. The only randomized controlled trial included in the current analysis (Prague-7 study) did not show benefit from routine pre-procedural abciximab when compared with selective use (35\% of the patients in the control group) during intervention [14]. Many factors may contribute to this. First, the study allowed the inclusion of patients not only in cardiogenic shock, but also at risk for cardiogenic shock. Second, it tested the routine upfront use of abciximab. Third, the selective use of abciximab, when deemed necessary by the operator, was allowed in the control group. Similarly, the ADMIRAL trial did also not show benefit of GPI use in cardiogenic shock on the combined outcome of death, reinfarction, or urgent target-vessel revascularization [8]. Regarding long-term outcomes, although 1 study showed abciximab use was not an independent predictor of death at 1-year follow-up [16], 2 others showed results consistent with better survival at 1-year predicted by GPI $[15,17]$.

Overall, 30-day and 1-year mortality were both almost halved in the GPI group in our meta-analysis. This may be explained, in part, by GPI's high potency, rapid onset of action, and IV route of administration: these characteristics offer it a special role in unstable patients. Until now, the most common P2Y12 inhibitors, except for cangrelor, have been available only in pill form. Hence, in the context of shock, many patients may not have a patent oral route and, even if they do, gastroparesis and delayed absorption may impair the efficacy of these antiplatelet drugs; additionally, these drugs usually have a longer time to platelet inhibition onset, even in stable patients. A report showed that in comatose patients after cardiac arrest undergoing PCI, clopidogrel loading did not significantly affect platelet function during the first $48 \mathrm{~h}$. This contrasted with eptifibatide, which produced profound platelet inhibition [24].

\section{Angiographic success: TIMI 3 flow after PCI}

Our results showed that GPI use adjunctive to standard therapy was associated with a 2-fold increase in the probability of achieving TIMI 3 flow after PCI. Except for the Prague-7 trial, which found no differences in TIMI flow after PCI between groups [14], all studies

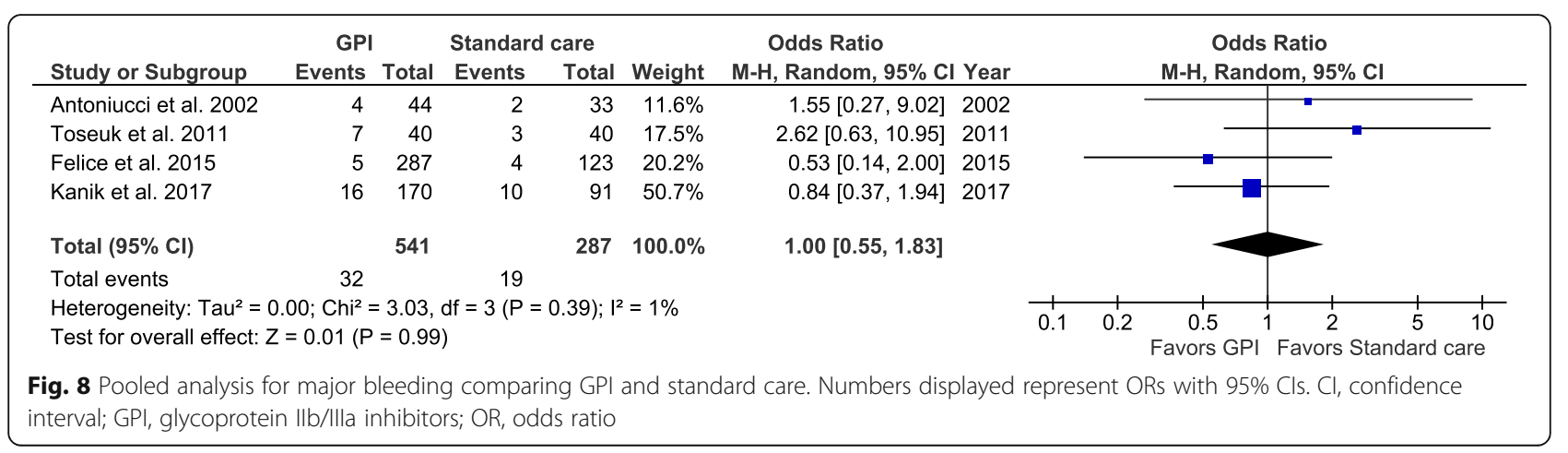




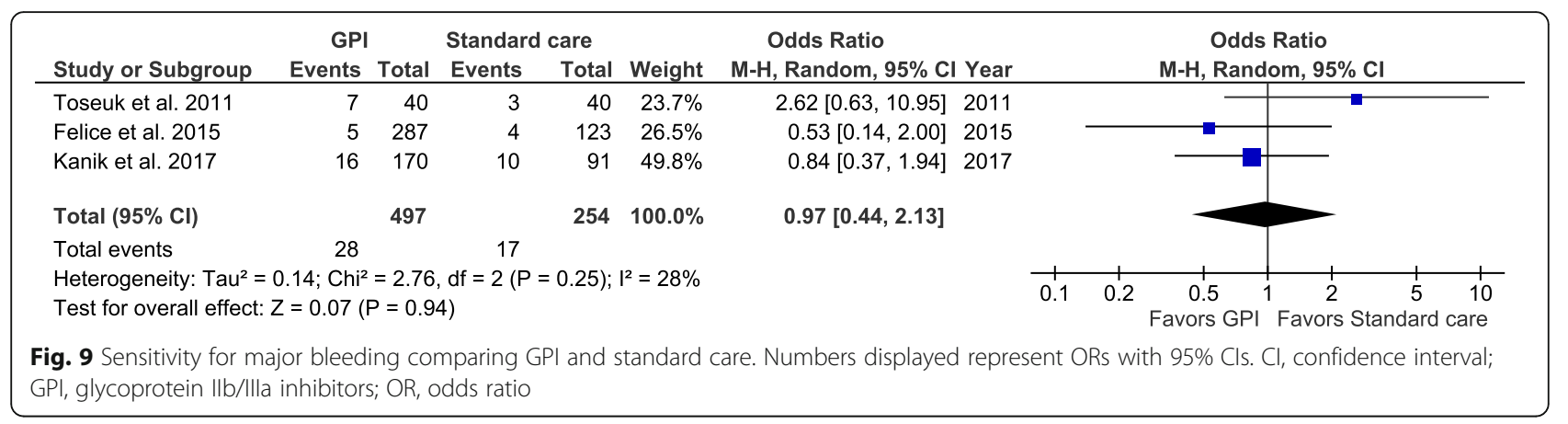

reporting this data are concordant with our results (73$79 \%$ in the GPI group vs. $55-65 \%$ in the standard care group) $[11,12,16,17]$. These results reinforce the efficacy of GPI in this setting, since most of the studies included patients whose GPI was prescribed at the discretion of the operator. This probably means, according to the actual guideline recommendations, that most of the patients receiving GPI had a higher thrombotic load and, even so, TIMI 3 flow after PCI was more likely in this group.

\section{Safety endpoints: effect on major bleeding}

In our meta-analysis, GPI showed a good safety profile. Despite differing criteria for definitions of major bleeding, reports of major bleeding varied from 1 to $10 \%$ in the GPI group and 3 to $12.5 \%$ in the standard treatment group [13, $14,16,17]$. There was consistency between studies that GPI use did not increase the risk of major bleeding compared to standard treatment [13, 14, 16, 17]. Although theoretically GPI adjunctive use could contribute to increased bleeding risk, an important consideration may be the fact that most of the studies included patients treated with GPI at the discretion of the operator. In our metaanalysis, no difference between groups regarding age was noted; other important bleeding risk factors and comorbidities may have varied between groups and were probably important considerations in the operators' decisions. This may induce a selection bias for which we were not able to control. Also, minor differences in major bleeding definitions varied between studies and minor bleedings were not reported in all the included studies.

\section{Limitations}

Most of the studies included had an observational design, and there were also some minor differences in the inclusion criteria for each study, including heterogeneity in the definitions of cardiogenic shock and enrolling patients admitted with cardiac arrest but not shock. Most of the studies were also conducted in the era of clopidogrel and may reflect different standards of care, not only regarding antiplatelet therapy but also revascularization and angioplasty strategies. We sought to overcome some of these limitations by conducting a sensitivity analysis. Whether or not these results would be replicated in the setting of the generalized use of more potent P2Y12 inhibitors with a more rapid onset of action is still unknown.

\section{Conclusion}

GPI therapy as an adjunct to standard treatment in acute MI patients with cardiogenic shock is associated with improved short- and long-term survival without an increased bleeding risk. These results warrant further randomized controlled trials to assess GPI value in these patients and in the context of new revascularization strategies.

\section{Abbreviations \\ MI: Myocardial infarction; GPI: Glycoprotein Ilb/llla inhibitors; ACS: Acute coronary syndrome; STEMI: ST-elevation myocardial infarction; IV: Intravenous; $\mathrm{PCl}$ : Percutaneous coronary intervention; LVEF: Left ventricular ejection fraction; IABP: Intraaortic balloon pump; TIMI: Thrombolysis in myocardial infarction; OR: Odds ratio; Cl: Confidence intervals}

\section{Acknowledgements}

None.

\section{Authors' contributions}

CS and RT designed the work and made the acquisition, analysis, and interpretation of the data and draft of the work. DC and JL designed the work and revised it. BO made the analysis and interpretation of the data. MC and $L N$ revised the work. All authors read and approved the final manuscript.

\section{Funding \\ None.}

\section{Availability of data and materials}

The datasets used and/or analyzed during the current study are available from the corresponding author on reasonable request.

Ethics approval and consent to participate Not applicable.

\section{Consent for publication}

Not applicable.

\section{Competing interests}

The authors declare that they have no competing interests.

\section{Author details}

'Serviço de Cardiologia, Centro Hospitalar e Universitário de Coimbra, Quinta dos Vales, 3041-801 Coimbra, Portugal. ${ }^{2}$ Coimbra Institute for Biomedical Research, Coimbra, Portugal. ${ }^{3}$ Faculdade de Medicina da Universidade de Coimbra, Coimbra, Portugal. 
Received: 17 September 2020 Accepted: 26 October 2020

Published online: 11 November 2020

\section{References}

1. VanDiepen S, Katz J, Albert N, Henry T, Jacobs A, Kapur N, et al. Contemporary management of cardiogenic shock. Circulation. 2017;136: e232-68. https://doi.org/10.1161/CIR.0000000000000525.

2. Kolte D, Khera S, Aronow WS, Mujib M, Palaniswamy C, Sule S, et al. Trends in incidence, management, and outcomes of cardiogenic shock complicating ST-elevation myocardial infarction in the United States. J Am Heart Assoc. 2014;3:e000590.

3. Wayangankar SA, Bangalore S, McCoy LA, Jneid H, Latif H, Karrowni W, et al. Temporal trends and outcomes of patients undergoing percutaneous coronary interventions for cardiogenic shock in the setting of acute myocardial infarction. J Am Coll Cardiol Cardiovasc Interv. 2016;9(4):341-51. https://doi.org/10.1016/j.jcin.2015.10.039.

4. Omer M, Garberich R, Sharkey SW, Brilakis E, Sorajja P, Henry TD, et al. Acute and stable ischemic heart disease. J Am Coll Cardiol. 2020;75(11):118. https://doi.org/10.1016/50735-1097(20)30745-2.

5. De Luca G, Navarese E, Marino P. Risk profile and benefits from Gp IIb-Illa inhibitors among patients with ST-segment elevation myocardial infarction treated with primary angioplasty : a meta-regression analysis of randomized trials. Europ Heart J. 2009;30(22):2705-13.

6. Karathanos A, Lin Y, Dannenberg L, Parco C, Schulze V, Brockmeyer M, et al. Systematic review/meta-analysis routine glycoprotein IIb /IIla inhibitor therapy in ST-segment elevation myocardial infarction: a meta-analysis. Can J Cardiol. 2019;35(11):1576-88. https://doi.org/10.1016/j.cjca.2019.05.003.

7. Huber K, Holmes DR Jr, van't Hof AW, Montalescot G, Aylward PE, Betriu GA, et al. Use of glycoprotein Ilb / Illa inhibitors in primary percutaneous coronary intervention: insights from the APEX-AMI trial. Eur Heart J. 2010; 31(14):1708-16.

8. Montalescot G, Barragan P, Wittenberg O, Eccolan P, Elhadad S, Villain P, et al. Platelet glycoprotein IIb / IIla inhibition with coronary stenting for acute myocardial infarction. N Engl J Med. 2001;344(25):1895-903.

9. Uk CB, Germany GH, Germany AK, Lenzen MJ, Denmark EP, Vranckx P. ESC Guidelines for the management of acute myocardial infarction in patients presenting with ST -segment elevation The Task Force for the management of acute myocardial infarction. Eur Heart J. 2017, 2018;39(2):119-77.

10. Chapman MJ, Fraser RJ, Bryant LK, Holloway RH, Nguyen NQ. The effects of sedation on gastric emptying and intra-gastric meal distribution in critical illness. Intensive Care Med. 2008:34(3):454-60.

11. Giri S, Mitchel J, Azar RR, Kiernan FJ, Fram DB, Mckay RG, et al. Results of primary percutaneous transluminal coronary angioplasty plus abciximab with or without stenting for acute myocardial infarction complicated by cardiogenic shock. Am J Cardiol. 2002;89(01):1-6.

12. Chan AW, Chew DP, Bhatt DL, Moliterno DJ, Topol EJ, Ellis SG. Long-term mortality benefit with the combination of stents and abciximab for cardiogenic shock complicating acute myocardial infarction. Am J Cardiol. 2002;89(2):132-6.

13. Antoniucci D, Valenti R, Migliorini A, Moschi G, Trapani M, Dovellini EV, et al. Abciximab therapy improves survival in patients with acute myocardial infarction complicated by early cardiogenic shock undergoing coronary artery stent implantation. Am J Cardiol. 2002;90:353-7.

14. Tousek P, Rokyta R, Tesarova J, Pudil R, Belohlavek J, Stasek J, et al. Routine upfront abciximab versus standard periprocedural therapy in patients undergoing primary percutaneous coronary intervention for cardiogenic shock: the PRAGUE-7 study. An open randomized multicentre study. Acute Cardiac Care. 2011;13(February):116-22.

15. Bernat I, Abdelaal E, Plourde G, Bataille Y, Cech J. Early and late outcomes after primary percutaneous coronary intervention by radial or femoral approach in patients presenting in acute ST-elevation myocardial infarction and cardiogenic shock. Am Heart J. 2013;165(3):338-43. https://doi.org/10. 1016/j.ahj.2013.01.012.

16. De Felice F, Tomassini F, Fiorilli R, Gagnor A, Parma A, et al. Effect of abciximab therapy in patients undergoing coronary angioplasty for acute ST-elevation myocardial infarction complicated by cardiogenic shock. Circ J. 2015;79(July):1568-74.

17. Kanic V, Vollrath M, Penko M, Kanic Z. GPIllb-Illa receptor inhibitors in acute coronary syndrome patients presenting with cardiogenic shock and / or after cardiopulmonary resuscitation. Heart Lung Circ. 2018;27(1):73-8. https://doi.org/10.1016/j.hlc.2017.02.011.
18. Neumann F, Zohlnhofer D, Fakhoury L, Ott I, Gawz M, Schomin A. Effect of glycoprotein Ilb/Illa receptor blockage on platelet-leukocyte interection and surface expression of the leucocyte integrin Mac-1 in acute myocardial infacrtion. J Am Coll Cardiol. 1999;34(5):1320-6.

19. Neumann F, Blasini R, Schmitt C, Alt E, Dirschinger J, Gawaz M, et al. Effect of glycoprotein $\mathrm{Ilb} / \mathrm{Ill}$ a receptor blockade on recovery of coronary flow and left ventricular function after the placement of coronary-artery stents in acute myocardial infarction. Circulation. 1998;98(24):2695-701.

20. Hochman JS, Sleeper LA, Webb JG, et al. Early revascularization in acute myocardial infarction complicated by cardiogenic shock. SHOCK Investigators. Should we emergently revascularize occluded coronaries for cardiogenic shock. N Engl J Med. 1999;341(9):625-34.

21. Szumita PM, Roberts RJ, Qamar A, Hack L, Rath D, Gawaz M, et al. Cangrelor in cardiogenic shock and after cardiopulmonary resuscitation: a global, multicenter, matched pair analysis with oral P2Y12 inhibition from the IABPSHOCK II trial. Resuscitation. 2019;137(December 2018):205-12. https://doi. org/10.1016/j.resuscitation.2019.02.008.

22. Klein LW, Shaw RE, Krone RJ, Brindis RG, Anderson HV, Block PC, et al. Mortality after emergent percutaneous coronary intervention in cardiogenic shock secondary to acute myocardial infarction and usefulness of a mortality prediction model. Am J Cardiol. 2005;96(1):35-41.

23. Hasdai D, Hattington R, Hochman J, Califf R, Battler A, Box J, et al. Platelet glycoprotein Ilb/llla blockage and outcome of cardiogenic shock complicating acute coronary syndromes without persistent ST-segment elevation. J Am Coll Cardiol. 2000;38(3):685-92.

24. Steblovnik K, Blinc A, Bozic-Mijovski M, Kranjec I, Melkic E, Noc M. Platelet reactivity in comatose survivors of cardiac arrest undergoing percutaneous coronary intervention and hypothermia. Eurolntervention. 2015;10(12):141824. https://doi.org/10.4244/EIJY14M05_02.

\section{Publisher's Note}

Springer Nature remains neutral with regard to jurisdictional claims in published maps and institutional affiliations.

\section{Ready to submit your research? Choose BMC and benefit from:}

- fast, convenient online submission

- thorough peer review by experienced researchers in your field

- rapid publication on acceptance

- support for research data, including large and complex data types

- gold Open Access which fosters wider collaboration and increased citations

- maximum visibility for your research: over $100 \mathrm{M}$ website views per year

At $\mathrm{BMC}$, research is always in progress.

Learn more biomedcentral.com/submissions 